\title{
AVALIAÇÃO COMPARATIVA DE TÉCNICAS PARA O ENSINO DE GEOGRAFIA: UMA ABORDAGEM A PARTIR DO CONCEITO DE CICLO HIDROLÓGICO
}

\author{
COMPARATIVE EVALUATION OF TECHNIQUES FOR GEOGRAPHY EDUCATION: AN APPROACH \\ FROM WATER CYCLE
}

\begin{abstract}
EVALUACIÓN COMPARATIVA DE TÉCNICAS PARA LA ENSEÑANZA DE LA GEOGRAFÍA: UN ENFOQUE A PARTIR DEL CONCEPTO DE CICLO HIDROLÓGICO

\author{
Fredson Pereira da Silva \\ Professor da Universidade Federal de Pernambuco, Petrolina.
}

Mestre em Ecologia Humana e Gestão Socioambiental - Universidade do Estado da Bahia - UNEB.

E-mail: fredson_psilva@hotmail.com
\end{abstract}

Lucas Costa de Souza Cavalcanti

Doutor em Geografia e professor adjunto na Universidade Federal do Pernambuco.

E-mail: lucascavalcanti3@gmail.com

\section{RESUMO}

O ciclo hidrológico descreve a existência e o movimento da água sobre, dentro e acima da Terra. O objetivo desse trabalho foi comparar técnicas de ensino que podem ser utilizadas pelos docentes nas suas aulas para facilitar a aprendizagem dos alunos em relação ao ciclo hidrológico. O presente trabalho foi desenvolvido na Escola Estadual NM 11, em uma turma de 34 alunos do $6^{\circ}$ ano do Ensino Fundamental. Seguindo a proposta do Cone da Aprendizagem, testou-se a hipótese de que jogos são mais eficientes para a aprendizagem do que vídeos. Dessa maneira confirmou-se que jogos podem ser uma alternativa mais eficaz do que vídeos para se trabalhar em sala de aula assuntos complexos como o ciclo da água.

Palavras-chave: Educação Geográfica; Recursos didáticos; Ciclo hidrológico.

\section{ABSTRACT}

The water cycle describes the existence and movement of water on, in and above the Earth. The objective of this work was to compare teaching techniques that can be used by teachers in their classes to facilitate students' learning in relation to the hydrological cycle. The present work was developed in the State School NM 11, in a class of 34 students of the 6th year of Elementary School. Following the proposal of The Cone of Learning, we tested the hypothesis that games are more efficient for learning than videos. Thus, it has been confirmed that games can be a more effective alternative than videos to work complex subjects in the classroom, such as the water cycle.

Keywords: Geographic Education; Educational resources; Water cycle.

\section{RESUMEN}

El ciclo hidrológico describe la existencia y el movimiento del agua sobre, dentro y por encima de la Tierra. El objetivo de este trabajo fue comparar técnicas de enseñanza que pueden ser utilizadas por los docentes en sus aulas para facilitar el aprendizaje de los alumnos en relación al ciclo hidrológico. El presente trabajo fue desarrollado en la Escuela Estadual NM 11, en una clase de 34 alumnos del $6^{\circ}$ año de la Educación Inicial. Siguiendo la propuesta del Cono del Aprendizaje, se buscó probar la hipótesis de que los juegos son más eficientes para el aprendizaje que los videos. De esta manera se ha confirmado que los juegos pueden ser una alternativa más eficaz que los videos para trabajar en el aula temas complejos como el ciclo del agua.

Palabras-clave: Educación Geográfica; Recursos didácticos; Ciclo hidrológico. 


\section{INTRODUÇÃO}

A água é um elemento fundamental para a existência da vida no planeta Terra. O ciclo hidrológico (Figura 1) descreve a existência e o movimento da água sobre, dentro e acima da Terra. Ele nos revela que a água, sempre está mudando, passa de um estado a outro da matéria, sempre retornando ao ponto inicial (PASSOS, 2009). O ciclo hidrológico é um conceito atrativo na à Educação Geográfica.

Para Miranda, Oliveira e Silva (2010), o ciclo da água consiste numa sucessão de etapas, em que a água parte de um estágio inicial até retornar à posição primitiva. Esse processo ocorre pela circulação fechada da água entre a superfície terrestre e a atmosfera, sendo movida principalmente pela energia solar em associação com a força gravitacional e à circulação atmosférica (LIMA, 2008).

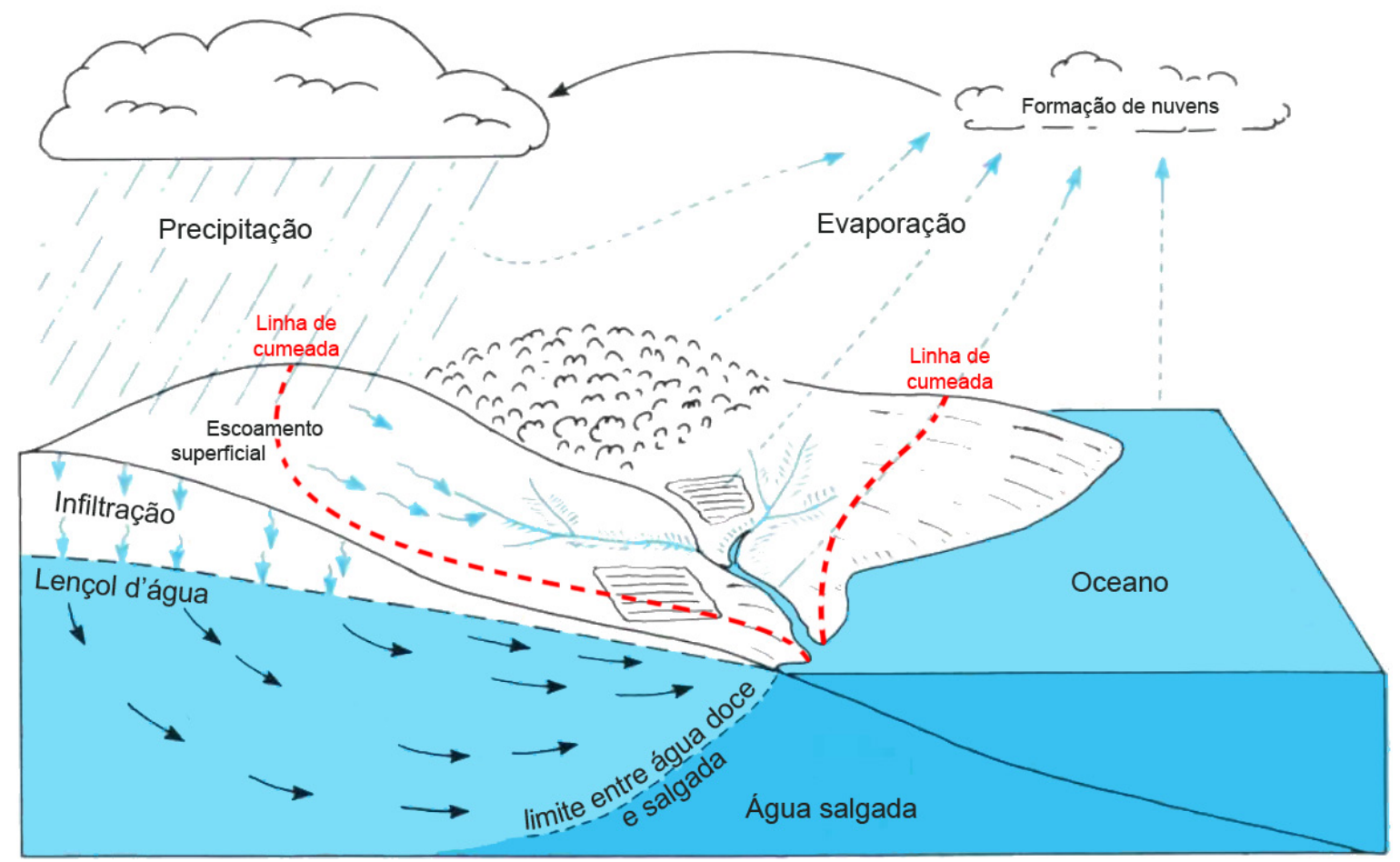

Figura 1 - Ciclo Hidrológico.

Fonte: Wikimedia Commons.

As principais etapas do ciclo hidrológico incluem: evapotranspiração, precipitação, interceptação, infiltração e escoamento (MIRANDA; OLIVEIRA; SILVA, 2010). Evapotranspiração é o nome dado à água que é perdida do ambiente físico (solo e corpos hídricos) para atmosfera pela evaporação, junto a água que é perdida pela transpiração dos seres vivos.

Após a evapotranspiração ocorre a transformação do vapor de água em nuvem e, 
em seguida, a precipitação, que é a chuva. A água precipitada pela chuva pode atingir diretamente a superfície (terrestre ou aquática) ou pode ser interceptada pelas copas das árvores ou qualquer outro tipo de cobertura (asfalto). Parte da água que chega ao solo termina por infiltrar, passando da superfície para o subsolo, muitas vezes se acumulando e formando uma reserva subterrânea (aquífero). Por fim, a água na superfície ou abaixo dela pode escoar declive abaixo, principalmente em relevos acidentados. Este escoamento pode ser tanto superficial quanto subterrâneo (MIRANDA; OLIVEIRA; SILVA, 2010).

Os processos acima referidos são comuns ao ciclo hidrológico em todas as regiões do globo, contudo, as taxas em que tais processos operam se diferenciam geralmente em função do clima, relevo e capacidade de armazenamento de água do substrato (CHRISTOFOLETTI, 1999).

\section{Ensinando o ciclo hidrológico}

Em relação ao ensino do ciclo hidrológico, alguns estudos têm sido realizados sobre o assunto. Ribeiro (2007), por exemplo, utilizou a interdisciplinaridade por meio da concepção de ciclo da água em uma bacia de drenagem em Campinas, SP. Em uma escola pública municipal, com o auxílio de duas professoras que ministram Geografia e Ciências para alunos da $5^{\circ}$ série $/ 6^{\circ}$ ano, desenvolvendo atividades continuadas em relação às questões ambientais, cujo objetivo era o ciclo hidrológico, a partir de uma microbacia de drenagem, percebeu-se uma dificuldade no tratamento do ciclo da água. Contudo, a partir de atividades simplificadas, obteve-se um avanço com atividades de campo na aprendizagem dos alunos e professores.

Outro exemplo é o trabalho de Freschi e Ramos (2009), que realizou o estudo da reconstrução do conhecimento dos alunos sobre o ciclo da água por meio de unidade de aprendizagem. Investigou escolas da região de Erechim-RS para saber dos alunos sua compreensão em relação ao ciclo da água, testando seus conhecimentos prévios que foi o norteador do seu trabalho, desenvolvendo questionário e visitas técnicas para reforçar na aprendizagem. Foi concluído, que é preciso conhecer a comunidade escolar, partir dos co- 
nhecimentos prévios relacionados à teoria e à prática e oferecer atividades diversificadas que contribuam para que os alunos atribuam novos significados aos fenômenos.

Merece destaque o trabalho de Silveira, Ataíde e, Freire (2009), que executaram atividades lúdicas no ensino de ciências, buscando uma adaptação metodológica através do teatro para comunicar a ciência a todos. Eles trouxeram um relato de duas experiências com este objeto de pesquisa ao longo dos anos de 2004 e 2005: "A trupe da magia" e "O ciclo da água", em alguns eventos de divulgação científica. Os mesmos concluíram que o teatro pode despertar o interesse dos estudantes, visto que possibilita trabalhar dados da ciência de forma lúdica.

Quanto à produção de material didático, o tema ciclo hidrológico também vem sendo abordado. Sobre isso, Martins, Gonçalves, Carneiro (2011), falam a respeito do ciclo hidrológico como chave analítica e interpretativa para o ensino de geociências. Os autores abordaram a apresentação do tema nos livros didáticos, caracterizando a abordagem de cada livro.

Utilizando linguagem e ambiente de programação computacional para educação (ToonTalk), Santos (2009), propôs a modelagem de sistemas experimentais com o tema do ciclo hidrológico. Neste estudo, seis alunos do ciclo básico foram escolhidos para aplicar o ToonTalk na modelagem do ciclo hidrológico com o objetivo de fortalecer seu conhecimento em relação à água.

\section{O cone da aprendizagem de Edgar Dale: perspectivas para a geografia}

O Cone da Experiência ou da Aprendizagem é uma representação gráfica que permite explicar os diferentes processos educativos (métodos) e materiais educativos (meios) que podem melhorar a capacidade de aprendizagem (GARDINER, 1998). Ele se apresenta numa forma cônica, (Figura 3) porque a base e a extremidade aguda representam maior e menor grau de impacto, respectivamente, na nossa capacidade de experimentar alguma aprendizagem nova. 


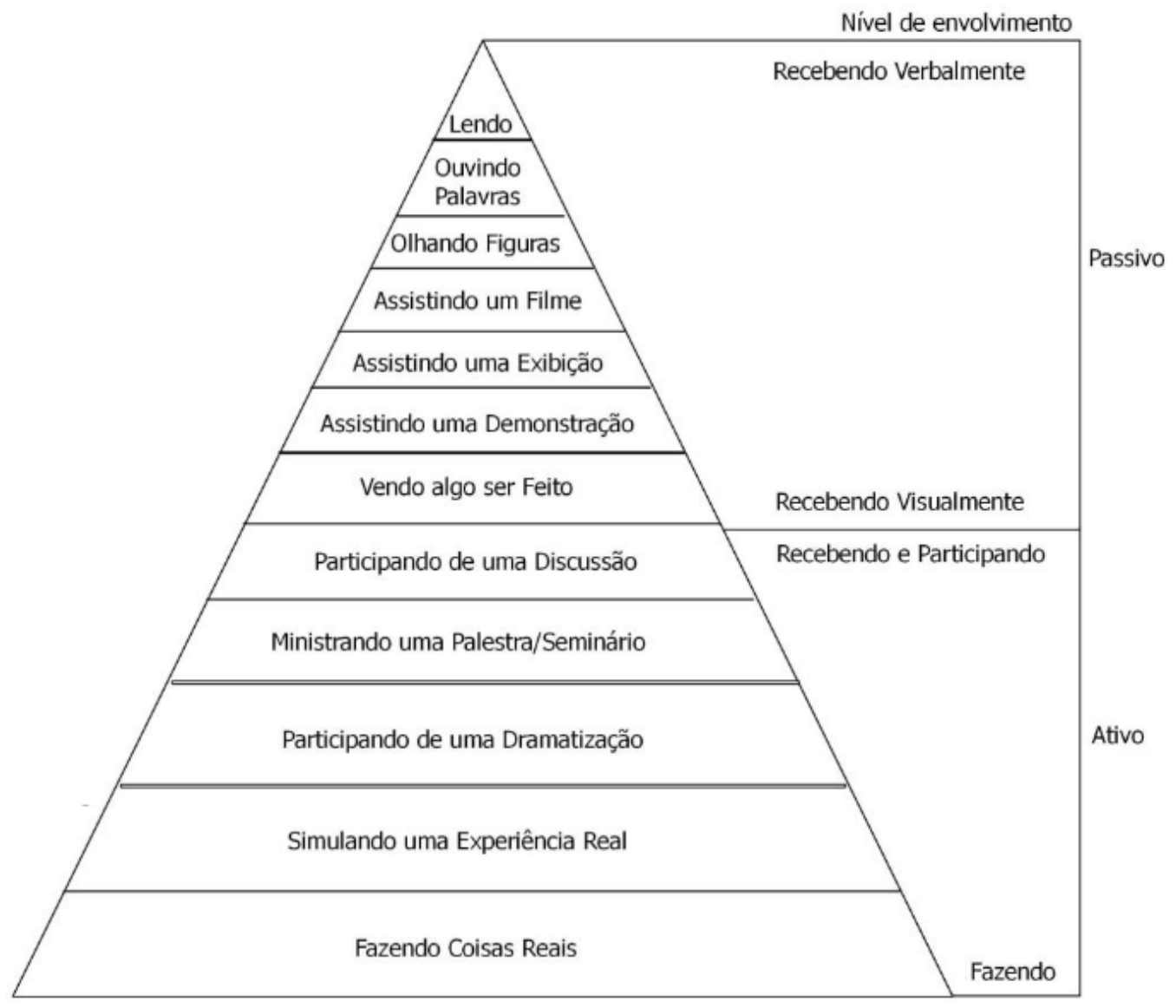

Figura 3 - Cone da aprendizagem.

Fonte: Dale, modificado por: Ferreira Junior et al., 2014.

O Cone da Experiência foi proposto por Edgar Dale em 1954 e publicado no livro "Métodos Audiovisuais para o Ensino". Segundo Dale. Neste modelo, as experiências que os indivíduos vivenciaram formam a base do Cone; a ideia é destacar o fato de que atividades que são executadas contribuem cada vez mais na facilidade de adquirir novos conhecimentos em relação àquela onde o aluno assume uma postura passiva (GARDINER, 1998; DALE, 1946).

Callai (2005) destaca que vivemos em uma época em que as dificuldades de aprendizagem têm aumentado grandemente, concentrando-se no modo como se realizam as atividades que permitem o exercício da vida escolar, em especial nas séries iniciais. Mas, por meio da proposta do cone da aprendizagem, pode-se facilitar a percepção dos alunos nas aulas de Geografia. O cone traz uma proposta de facilitar as aulas através de recursos que podem ser utilizados em sala de aula, onde os sentidos exercem uma função de aprendizagem (GARDINER, 1998). 
Dessa maneira, vários recursos didáticos podem ser utilizados nas aulas, estimulando a aprendizagem dos alunos, quais sejam: jogos, vídeo, informática, música e quadro-negro, textos - leitura, interpretação e elaboração, mapas e globos, grupos de trabalho, fórum simulado, jornal falado, dramatização etc. O conhecimento do cone da aprendizagem pode auxiliar na escolha metodológica, visando uma aprendizagem mais eficiente (SANTOS, 2010).

\section{Procedimentos metodológicos}

O trabalho foi desenvolvido em uma turma de 34 alunos do $6^{\circ}$ ano do Ensino Fundamental. Destes, 14 eram meninos (41\%) e 20 meninas (59\%). Com relação à idade, 5 alunos tinham 10 anos, 16 alunos tinham 11 anos e 13 alunos tinham 12 anos.

Seguindo a proposta do cone da aprendizagem, buscou-se testar a hipótese de que os jogos são mais eficientes para a aprendizagem do que os vídeos. Isso porque, conforme a proposta de Edgar Dale, jogos possuem a possibilidade educativa de ensinar qualquer coisa que compete ao indivíduo em seus conhecimentos e em sua compreensão da sociedade. Assim, este sujeito jogando e brincando, desenvolve as significações do aprender e enriquece a linguagem oral, bem como habilidades e estratégias, capacitando-se para enfrentar com sucesso as situações do dia a dia (NASCIMENTO, 2003).

De outro modo, vídeos exercem a função de reforçar os métodos tradicionais na transmissão dos conhecimentos; entretanto, também podem levar a transformar a comunicação pedagógica, trazendo à sala de aula um tipo de mensagem, ou linguagem audiovisual que fixa a imagem animada e os sons sincronizados, criando alguns obstáculos e não contribuindo no suporte do conhecimento (CINELLI, 2003).

Ainda de acordo com o cone da aprendizagem, o jogo é uma das mais eficazes técnicas para construção do conhecimento, pois por meio das atividades práticas, o estudante compreende melhor o assunto tratado. Dessa maneira, o discente, imitando a experiência de realizar aquilo que está sendo ensinado, chega ao êxito, tornando-se um agente ativo do processo de aprendizagem (SANTOS, 2010). 
Alguns autores sugerem uma integração entre vídeo e jogo. Sobre isso, em relação ao resultado do uso combinado de vídeos e jogos em sala de aula, Cinelli (2003, p. 54), defende que:

É importante que as atividades feitas em seguida a vídeo-aula coloquem em jogo os conteúdos trabalhados no vídeo para que os alunos possam utilizar as informações que acabaram de receber. Dessa forma, a possibilidade de assimilação dessas informações torna-se muito maior.

A procura por informações foi iniciada a partir da leitura de teses, dissertações, monografias, periódicos e reportagens em sites especializados, com o objetivo de registrar as principais dificuldades apresentadas pelos alunos em conhecer o ciclo hidrológico.

Em seguida, realizou-se uma série de atividades em sala de aula, de modo a testar a hipótese aventada anteriormente. Nesse sentido, o trabalho foi desenvolvido nas seguintes etapas:

- Apresentação da pesquisa;

- Aplicação do questionário socioeconômico-cultural;

- Aplicação de questionário sobre o ciclo hidrológico;

- Separação da turma em dois grupos, 'A' e 'B';

- Aplicação de videoaula sobre ciclo hidrológico para o grupo 'A';

- Aplicação de jogo sobre o ciclo hidrológico para o grupo 'B';

- Segunda aplicação do questionário sobre o ciclo hidrológico;

- Comparação dos resultados.

A pesquisa foi apresentada aos alunos do $6^{\circ}$ ano, mostrando-lhes de que forma esses trabalhos seriam desenvolvidos, de que maneira os questionários seriam aplicados e como a turma foi dividida para a exibição do videoaula e aplicação do jogo educativo.

Em seguida, foram aplicados dois questionários. O primeiro deles foi um questionário socioeconômico elaborado com base na hipótese de que algumas características interferem na qualidade da aprendizagem, como: renda familiar, escolaridade dos pais e capital cultural (quantidade de livros em casa, e quantidade de livros lidos por ano).

O segundo tratou de detectar conhecimentos prévios relacionados ao ciclo da água 
sem consulta a nenhum material. No questionário, foram abordadas três temáticas: o que é o ciclo da água; quais são suas fases; e como o ciclo contribui na manutenção da vida na Terra.

Para a designação de cada aluno foi utilizada a primeira letra do nome em formato maiúsculo. Nos casos em que o nome de dois alunos começa com a mesma letra inicial, utilizamos a primeira e a última letra do nome, ambas em formato maiúsculo. Por exemplo, a letra $\mathrm{F}$ refere-se ao aluno com inicial de nome $\mathrm{F}$ e as letras JM referem-se ao aluno com inicial de nome $J$ e final $M$.

Os alunos foram agrupados aleatoriamente em dois grupos de 17 pessoas, sem distinção de cor, gênero, idade ou outro critério. Optou-se por essa divisão com o intuito de interferir o mínimo possível na resposta às atividades que foram desenvolvidas com a turma.

Após a aplicação do questionário, foi exibido um vídeo para os estudantes do primeiro grupo. O vídeo escolhido foi desenvolvido pela NASA e mostra de forma educativa as fases do ciclo da água. O material tem por título “o ciclo da água”, possui 07:43 minutos de duração e foi elaborado no ano de 2010.

O vídeo iniciou com a apresentação do aquecimento das águas do oceano pela radiação solar, seguido do processo de a evaporação e formação das nuvens que precipitam a chuva no planeta. Durante o dia, e logo após, escorre uma parte da água para o solo. Outra parte infiltra e vai para os rios e lagos por meio do lençol freático. Posteriormente, evapora e novamente torna à atmosfera e precipita em forma de neve, que cai sobre as montanhas geladas. O ciclo também é exibido durante a noite. Em seguida, o vídeo é repetido e, em todo percurso da água, suas fases são detalhadas com a utilização de uma legenda.

Para o outro grupo, foi utilizado um Software educacional sobre o ciclo da água. O jogo selecionado foi desenvolvido pelo Centro de Aprendizagem sobre a Água, uma empresa que produz jogos relacionados aos recursos hídricos. O jogo é administrado pelo Banco Internacional de Objetos Educacionais, com repositório que possui objetos educacionais de acesso público, em vários formatos e para todos os níveis de ensino, possui como detentor do direito autoral o Ministério da Educação (MEC). Trata-se de um jogo online "Atividades sobre Água”, para desenvolver o conhecimento do aluno sobre a impor- 
tância da utilização racional dos recursos hídricos.

O jogo pode ser utilizado por 3 a 6 jogadores de uma vez, com uma duração, que pode variar de 20 a $40 \mathrm{mim}$, dependendo da estratégia que cada um vai utilizar na competição. O que podemos encontrar no jogo é que o desafio para os jogadores possui um conjunto de atividades, jogos e testes sobre o tema água.

Na primeira atividade, os jogadores devem arrastar as gotas de água para a posição correta, para saber a distribuição da água no planeta. Logo após, a segunda atividade, os jogadores precisam assinalar corretamente seis utilidades que a água possui no seu ciclo e, depois, verificar se estão corretas ou não. Se não estiver correta, uma animação diz que a atividade deve ser refeita.

A terceira atividade consiste em completar os provérbios em frases relacionadas à água da chuva e aos componentes do ciclo da água. A quarta atividade pede para arrastar as setas para a posição correta do ciclo da água, mostrando suas fases especificadas claramente. Na quinta atividade, pede-se para arrastar a quantidade de litros de água utilizados em casa para despertar no aluno princípios de conservação da água. Por fim, é preciso montar um puzzle, que é um jogo de paciência, mostrando a distribuição de água.

Após o desenvolvimento das atividades, esperou-se 7 dias depois dos quais se retornou à escola para a aplicação do mesmo questionário, que foi aplicado inicialmente. Em seguida, as respostas do questionário foram tabuladas para comparação dos resultados. Para tanto, foram confeccionados gráficos, em Microsoft Excel, para verificação das mudanças nos resultados obtidos nas duas etapas de aplicação dos questionários e observar se o cone da aprendizagem, verdadeiramente, possui validade.

\section{Resultados e discussão}

O primeiro grupo foi assistir a um videoaula sobre o ciclo hidrológico. Esse vídeo foi projetado no quadro branco da escola, e logo no início os alunos ficaram todos curiosos devido às formas que as nuvens faziam na tela, como a chuva caía e penetrava no solo, como as ondas no mar se elevavam e as formas da montanha com neve. Logo após, mos- 
traram-se as fases em detalhe para que eles percebessem, especificando como cada uma acontecia.

Em seguida, os outros alunos começaram a jogar depois da autorização. Foi pedido para que seguissem passo a passo e, dessa forma, foi sendo realizado o jogo. Quando um aluno perguntou: “já acabamos essa primeira fase, já estamos na terceira fase podemos passar para outra?", a resposta foi imediata que poderia sim, todos os que estavam jogando conseguiram executar bem as atividades; apenas dois grupos tiveram um pouco de dificuldade em função de não saberem manusear bem o mouse, mas logo em seguida, todos conseguiram executar as atividades com êxito.

Posteriormente, esperou-se 7 dias $^{1}$ e foi aplicado o questionário final, com as mesmas perguntas do primeiro em relação ao ciclo da água para comparamos as respostas dos alunos em relação aos avanços na resolução das questões e descobrir se foi o vídeo ou o jogo que teve maior validade no processo educativo. Dessa maneira, chegou-se aos resultados da aplicação dos questionários, apresentados nos gráficos a seguir.

Seguindo assim, pode-se perceber que as respostas dos alunos, num primeiro momento, não foram satisfatórias, no sentido de que não continham elementos essenciais dos conceitos trabalhados (Gráfico 3). Do total dos alunos, 56\% deles apresentaram desenvolvimento satisfatório ao responderem as questões de forma que entendem o ciclo da água e seu funcionamento, citando algumas fases. Os demais $44 \%$ apresentaram desempenho regular, não conseguindo responder às questões ou apresentando respostas vagas, além de não demonstraram compreender a importância do ciclo da água para o planeta. Foram consideradas como respostas satisfatórias aquelas em que o aluno conhece o ciclo da água, mas não sabe descrever como ele acontece, citando apenas algumas fases.

$1 \quad$ Em sua proposta original, Edgar Dale avaliou a capacidade de lembrança do conteúdo após um período de 15 dias. Neste trabalho o tempo foi reduzido em função de o período de férias dos alunos estar próximo. 
Gráfico 3 - Desempenho dos alunos nas questões do Ciclo Hidrológico.

\section{Alunos}

- Desempenho regular; $15 ; 44 \%$

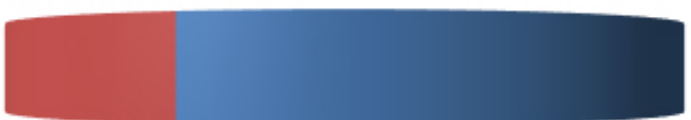

- Desempenho satisfatório; 19; $56 \%$

- Desempenho satisfatório

Desempenho regular

Fonte: dados da pesquisa, 2015.

Dessa maneira, perceber as respostas iniciais desses alunos na sua escrita, e também as suas respostas finais logo após a aplicação do último questionário. A primeira pergunta a que os alunos responderam durante o questionário inicial e final foi: "O que é ciclo da água?". Entre as respostas, destacamos algumas que melhor representam o grupo de alunos:

É a transformação da água (JS).

Percebe-se que, inicialmente, o aluno JS possuía uma ideia simples do fenômeno natural do ciclo da água, e após a realização do segundo questionário, a resposta foi informada de maneira simples, porém atendendo ao solicitado pela questão. A seguir, é apresentada, respectivamente, a segunda resposta do aluno JS à mesma questão:

É quando a água evapora e sobe formando as nuvens de chuva e ela desce em forma de chuva (JS).

Em relação à resposta regular, o aluno $\mathrm{H}$ mostra de forma simples a sua ideia sobre o ciclo da água.

É quando água evapora e vira gás $(\mathrm{H})$.

A seguir, é apresentada, respectivamente, a resposta do segundo questionário do aluno $\mathrm{H}$ :

É o fenômeno natural que ocorre quando água evapora e forma as nuvens (H).

A resposta regular prévia apresenta dados corretos, porém simples, enquanto na resposta final, logo após a aplicação das atividades, o aluno explica de modo claro e abrangente, confirmando o entendimento. Seguindo assim, percebe-se que as respostas dos alu- 
nos antes e depois da aplicação do questionário apresentaram relativa mudança, no sentido de se tornarem mais complexas e abrangentes. Contudo, essa diferença foi percebida de modo diferente entre os dois grupos considerados (os alunos que assistiram ao vídeo e os alunos que jogaram).

O gráfico 4 mostra a quantidade de respostas satisfatórias dos alunos que assistiram ao vídeo educativo. Percebe-se que as respostas dos alunos quase não sofreram mudança e nem mesmo os seus desenhos apresentaram diferenças significativas. Apenas 3 alunos $(17,6 \%)$ apresentaram uma maior quantidade de respostas satisfatórias e um deles $(5,9 \%)$ apresentou uma quantidade menor.

Essa pequena mudança pode ser atribuída ao fato de que o vídeo em geral tende apenas a fixar imagens animadas, não contribuindo significativamente na construção do conhecimento (CINELLI, 2003).

Gráfico 4 - Respostas dos alunos que assistiram ao vídeo.

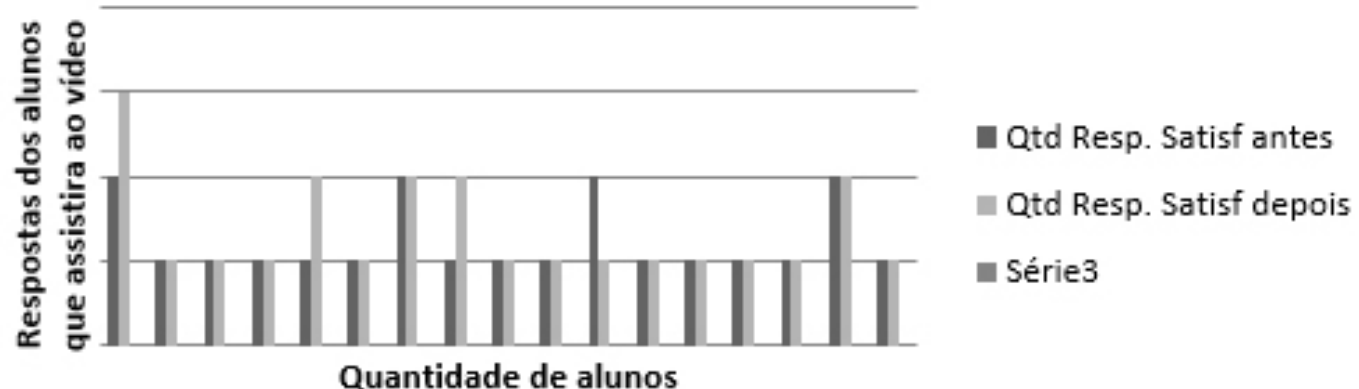

Fonte: dados da pesquisa, 2015.

De outra maneira, os alunos que jogaram puderam responder às questões mais de forma conceitual e identificar em seus desenhos as fases do ciclo hidrológico (Gráfico 5). Logo após a aplicação do jogo, a quantidade de respostas satisfatórias aumentou significativamente. Os 14 alunos (82\%) apresentaram uma maior quantidade de respostas satisfatórias e apenas um deles (5,9\%) apresentou uma quantidade menor. 
Gráfico 5 - Respostas dos alunos que jogaram.

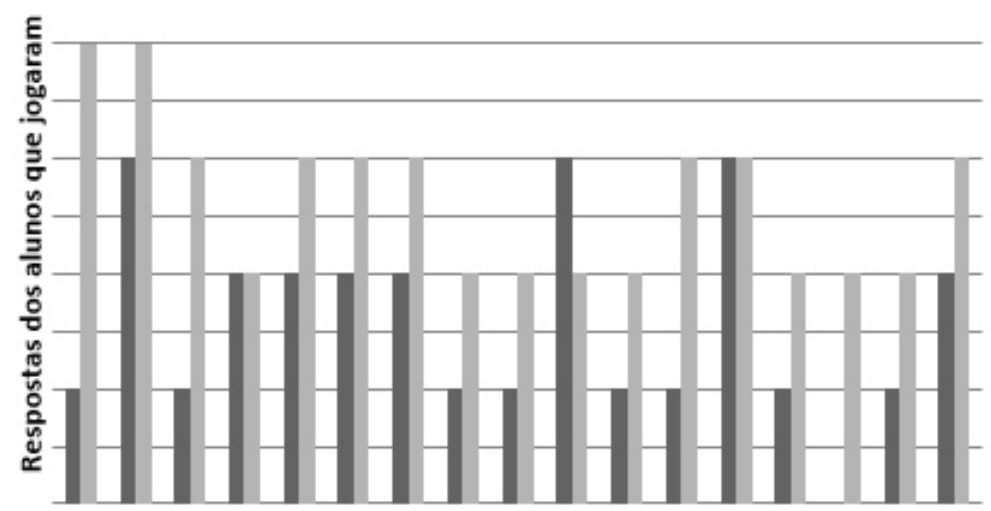

Quantidade de alunos
Q Qtd Resp. Satisf antes

Qtd Resp. Satisf depois

Fonte: dados da pesquisa, 2015.

Podemos atribuir o sucesso da aplicação do jogo ao fato de que o mesmo tem um potencial dinâmico para ampliar aspectos referentes aos significados que se desenvolvem durante a aprendizagem. Além disso, o jogo também contribui para o enriquecimento de características da linguagem oral e de conhecimento tático e de estratégia (NASCIMENTO, 2003).

Com o objetivo de identificar as diferenças em relação ao conhecimento prévio e ao conhecimento reconstruído durante a pesquisa, solicitamos, também, que os alunos fizessem um desenho sobre o fenômeno natural do ciclo da água na natureza no início da pesquisa. Foi utilizado um questionário inicial e outro desenho seguido do questionário final da atividade, pois, alguns dos alunos que não conseguiram escrever sobre o ciclo hidrológico desenharam as suas fases. Dessa forma Silva (2015, p. 92), defende que:

O desenho é, na atualidade, uma técnica projetiva de admirável validade e grandemente vantajosa, principalmente quando aplicada às crianças com menos idade, porque elas demonstram maior facilidade em expressar-se através de desenhos do que de palavras.

Os alunos que não conseguiram escrever sobre o ciclo da água, também pintaram os seus esboços para expressar o que eles entendem sobre os movimentos que água realiza no planeta.

Seguindo assim, os Parâmetros Curriculares Nacionais (PCNS) indicam os desenhos 
também como uma forma de alunos expressarem sua aprendizagem:

Desenhar é uma maneira de expressão característica desse momento da escolaridade e um procedimento de registro que deve ser valorizado pela Geografia. Mas o desenho agora começa a ganhar outros conteúdos como forma de representação, pois o aluno já percebe aquilo que desenha como imagens que permitem inferências sobre o real (BRASIL, 1998, p.4).

Analisando os desenhos realizados pelos alunos que assistiram ao vídeo, destacamos o desenho da aluna M (Figura 11), que demonstra, inicialmente, um conhecimento simples sobre o ciclo da água. De acordo com o desenho, percebemos o mar, que é um dos locais de onde a água evapora e a presença do sol que se faz necessário para ocorrência do fenômeno natural, irradiando calor para aquecer as águas para a evaporação e a presença da chuva simples.

Figura 11 - Desenho inicial da aluna M antes de assistir ao vídeo.

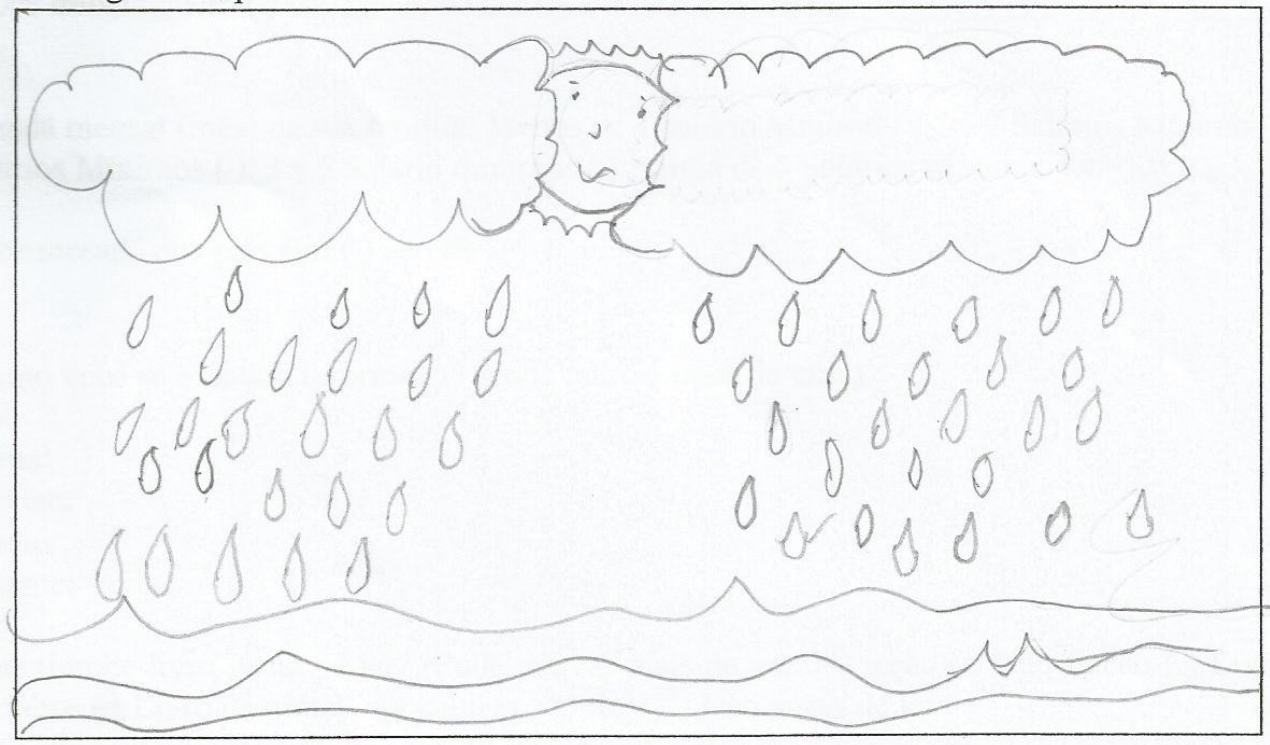

Fonte: dados da pesquisa, 2015.

Mesmo depois de assistir ao vídeo sobre o ciclo hidrológico, não se perceberam mudanças significativas no desenho da aluna $\mathrm{M}$, visto que o mesmo apresenta apenas cores, sem chuva (Figura 12). 
Figura 12 - Desenho final da aluna M depois de assistir ao vídeo.

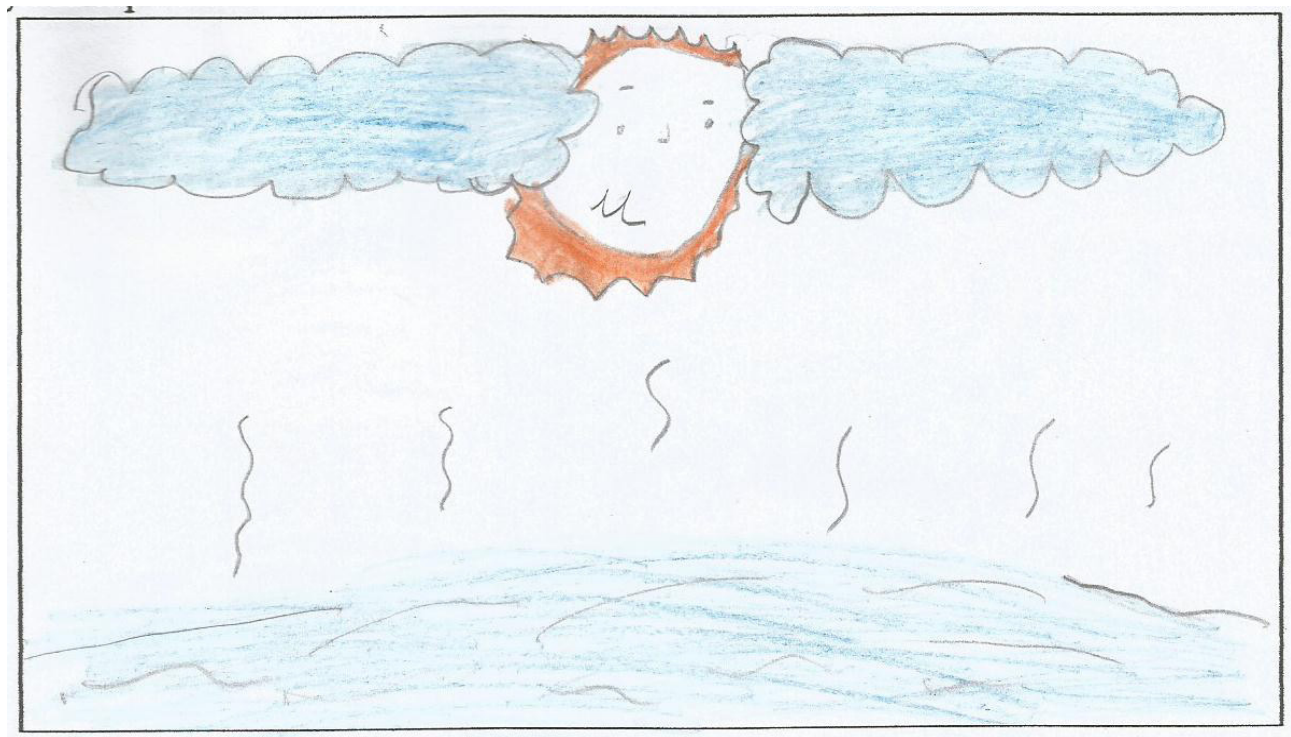

Fonte: dados da pesquisa, 2015.

O primeiro desenho sobre o fenômeno natural do ciclo da água apresentado pelo aluno 'A' mostra o sol aquecendo água que depois evapora, formando as nuvens seguindo da chuva (Figura 13). Além disso, de acordo com o desenho, só acontece o ciclo da água no mar, dificultando o entendimento do processo como um todo.

Figura 13 - Desenho do aluno A antes de participar do jogo.

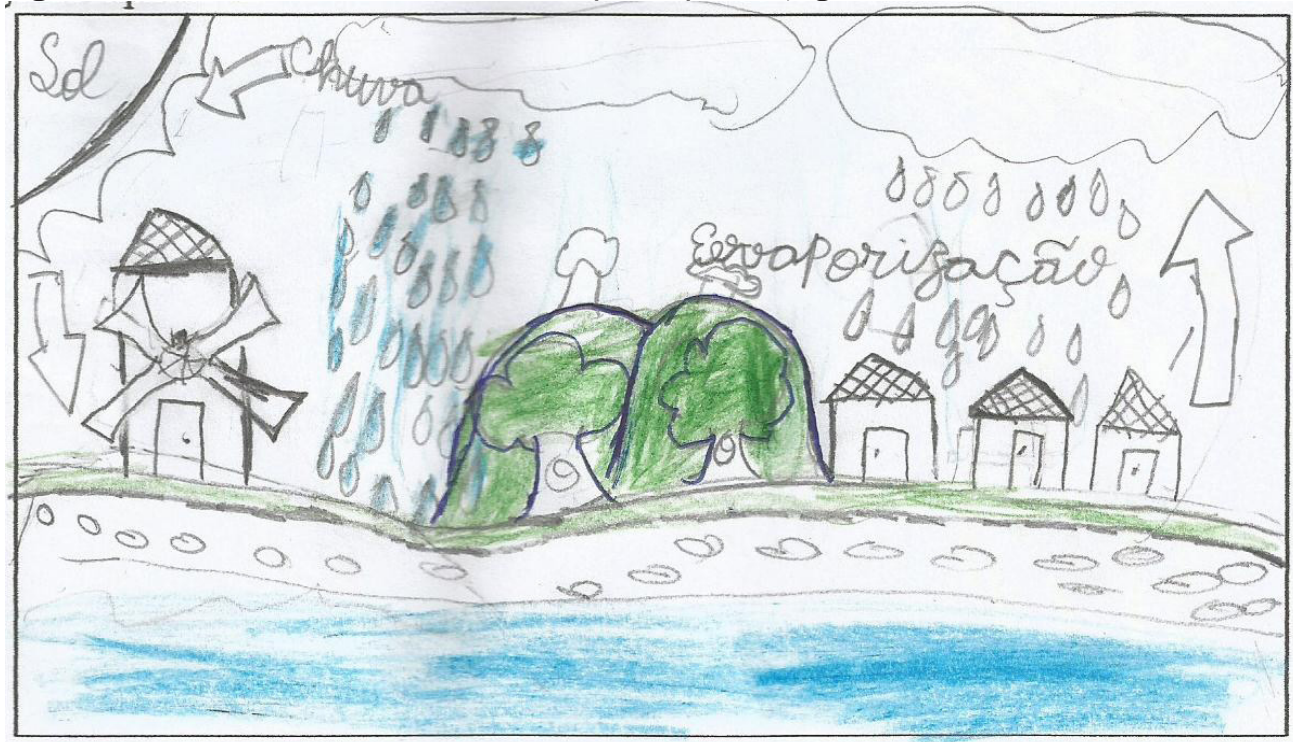

Fonte: dados da pesquisa, 2015.

Em seguida, o último desenho do aluno A (Figura 14) mostra o fenômeno do ciclo da água de uma forma mais completa: o sol irradia luz para a superfície, na qual água evapora 
e forma nuvens de chuva e, quando essa cai, provoca o escoamento da água e a infiltração no solo. Podemos perceber também, no desenho, a presença de casas e vegetações que apareciam no jogo educativo.

Figura 14- Desenho do aluno A depois de participar do jogo.

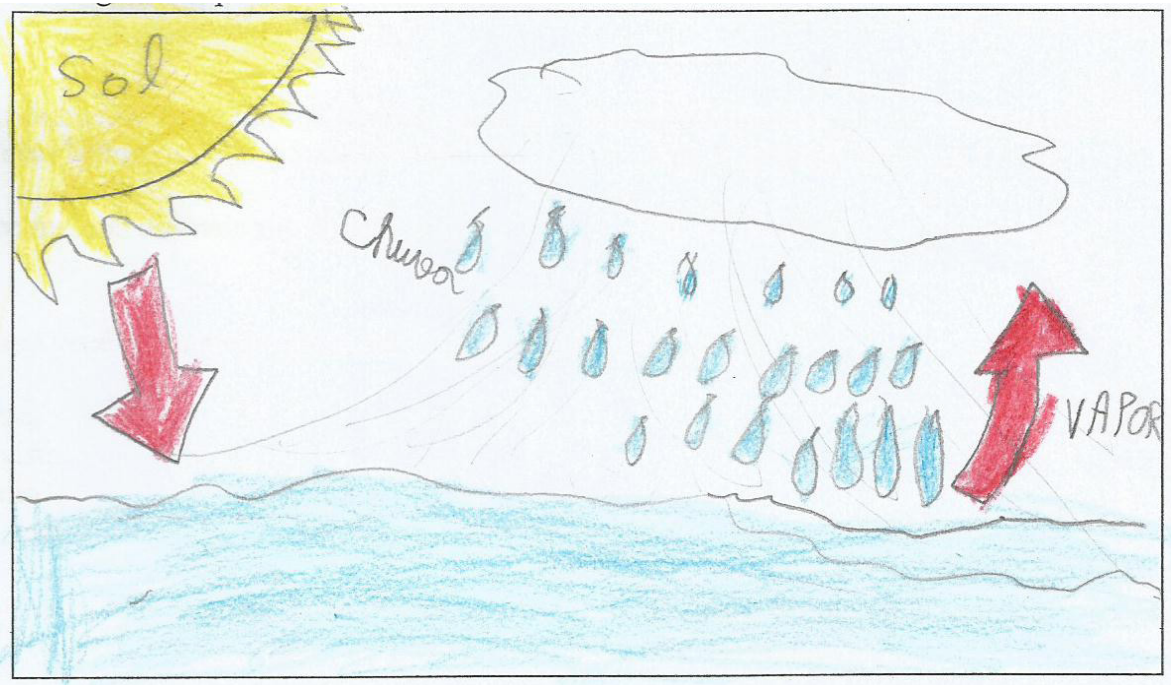

Fonte: dados da pesquisa, 2015.

\section{CONSIDERAÇÕES FINAIS}

Este trabalho buscou compreender o efeito que diferentes técnicas de ensino exercem sobre os resultados da aprendizagem. Comparou-se um jogo e um vídeo, trabalhando numa turma homogênea em termos de idade, escolaridade e faixa de renda. Os principais resultados sugerem que o jogo utilizado foi muito mais significativo para colaborar no processo de aprendizagem do que o vídeo escolhido.

Contudo, algumas questões permanecem em aberto. Uma delas diz respeito ao fato de que a diferença possa ter provido do tipo específico de vídeo e jogo que foram utilizados. Além disso, compreende-se que o quantitativo de estudantes avaliados mão permitiu uma análise estatística aprofundada.

Neste sentido, sugere-se ampliar a população estudada, bem testar diferentes vídeos e jogos. Na esteira destas considerações, o desenvolvimento de uma abordagem estatística seria de grande valia para um entendimento mais abrangente. De qualquer modo, os resultados indicam que a postura ativa dos alunos diante do conhecimento parece ser 
um caminho mais útil à educação geográfica, corroborando a teoria subjacente à ideia do cone da aprendizagem.

Entende-se que a realidade da educação é diferente do que é mostrado na teoria em sala de aula. Aulas enfadonhas em que os alunos não são chamados a participar oferecem pouco em termos de aprendizagem. Esse foi um dos desafios enfrentados no desenvolvimento deste trabalho: buscar a interação professor-aluno na participação efetiva e também o uso da estrutura física da escola, visando contribuir melhor no desenvolvimento da aprendizagem.

Portanto, este trabalho não termina aqui, espera-se que outras pesquisas possam ser desenvolvidas, comparando outros tipos de técnicas que venham contribuir na aprendizagem dos alunos, testando alternativas que possam influenciar na sua vida social e levá-los a pensar de forma diferente.

\section{REFERÊNCIAS}

BRASIL. Ministério da Educação- MEC, Secretaria de Educação Fundamental. Parâmetros Curriculares Nacionais: Geografia. Brasília: Ministério da Educação, 156p. 1998.

CALLAI, H. C. Aprendendo a ler o mundo: a Geografia nos anos iniciais do Ensino Fundamental. Caderno Cedes, Campinas, v. 25, n. 66. p. 227-247. 2005.

CHRISTOFOLETTI, A. Modelagem de sistemas ambientais. Ed. 1. São Paulo: Edgard Blucher, p.1-233, 1999.

CENTRO DE APRENDIZAGEM SOBRE ÁGUA. Disponível em: http://centrodeaprendizagem. vimagua.pt/jogos.htm. Acesso em: 13 mai. 2008.

CINELLI, N. P. F. A influência do vídeo no processo de aprendizagem. 72 f. Dissertação (Mestrado em Engenharia de Produção) - Universidade Federal de Santa Catarina, 2003.

DALE, E. Audio-Visual Methods in Teaching. NY: Dryden Press, 1946.

FRESCHI, M; RAMOS, M.G. Unidade de Aprendizagem: um processo em construção que possibilita o trânsito entre senso comum e conhecimento científico. Revista Electrónica de Enseñanza de las Ciencias. v.8, n.1, p.156-170. 2009.

GARDINER, T. Formação de formadores na educação participativa. In: Workshop Ateilier, p. 1-47. 1998.

LIMA, W. P. Análise física da bacia hidrográfica. In. ,. Hidrologia florestal aplicada 
ao manejo de bacias hidrográficas. Escola Superior de Agricultura “Luiz de Queiroz”. Departamento de Ciências Florestais, USP. Piracicaba: p.05-23. Cap.2, 2008.

MARTINS, J. R. S.; GONÇALVES, P. W.; CARNEIRO, C. D. R. O ciclo hidrológico como chave analítica interpretativa de um material didático em Geologia. Revista Ciência \& Educação, v. 17, n. 2, p. 365-382. 2011.

MIRANDA, R. A. C.; OLIVEIRA, M. V. S.; SILVA, D. F. Ciclo Hidrológico Planetário: Abordagens e Conceitos. Revista Geo UERJ, v. 1, n. 21, p.109-119. 2010.

NASA. Disponível em: https://www.youtube.com/watch?v=iohKd5FWZOE. Acesso em: 18 mai. 2015.

NASCIMENTO, R. S. Instrumentos para prática de educação ambiental formal com foco nos recursos hídricos. 237 f. Tese (Doutorado Engenharia de Produção e Sistemas) - Universidade Federal de Santa Catarina, Florianópolis, 2003.

PASSOS, M. M. Aspectos Relevantes da Poluição das Águas. 56 f. Monografia (Pós-Graduação em Direito Ambiental) - Universidade Candido Mendes, Rio de Janeiro, 2009.

RIBEIRO, S. R. Interdisciplinaridade por meio da concepção de ciclo da água em uma bacia de drenagem de Campinas, SP. 115 f. Dissertação (Mestrado em Ensino e História de Ciências da Terra) - Universidade Estadual de Campinas, Campinas -São Paulo, 2007.

SANTOS, L. M. M. Modelação de sistemas experimentais em ToonTalk para Ambientes Educativos: Ciclo da Água. 205 f. Dissertação (Mestrado em Matemática e Ciências da Natureza) - Universidade de Trás-os-Montes e Alto Douro, Vila Real, 2009.

SANTOS, L. M. M. Elaboração de material paradidático para educação ambiental com ênfase em atividades lúdicas. 86 f. Dissertação (Mestrado em Ensino de Ciências e Matemática) - Pontifícia Universidade Católica de Minas Gerais, 2010.

SILVA, G. P. A. Caatinga do Imaginário Infantil. 1. ed. Curitiba-PR: Appris, 171 p., 2015.

SILVEIRA, A. F.; ATAÍDE, A. R. P.; FREIRE, M. L. F. Atividades lúdicas no ensino de ciências: uma adaptação metodológica através do teatro para comunicar a ciência a todos. Revista Educar, Curitiba, n. 34, p. 251-262. 2009.

USGS. O ciclo da água. Disponível em: http://water.usgs.gov/edu/watercycleportuguese. html. Acesso em: 26 jun. 2015.

Artigo submetido em: 17/03/2019

Parecer em: 01/10/2019

Aprovado em: 08/11/2019 